\title{
Sonographic characteristics of median nerve neuropathy in Hansen's disease: a case-control study
}

\author{
Y. Muralidhar Reddya ${ }^{\mathrm{a}}$ Jagarlapudi M. K. Murthy ${ }^{\mathrm{a}}$, \\ Lalitha Pidaparthi ${ }^{\mathrm{a}}$, Shyam K. Jaiswal ${ }^{\mathrm{a}}$, E. S. S. Kiran ${ }^{\mathrm{a}}$, \\ Anusha Penneru $^{\mathrm{a}}$, Ravi Nukala ${ }^{\mathrm{a}} \&$ Sudhir Kumar ${ }^{\mathrm{b}}$ \\ ${ }^{a}$ Department of Neurology, CARE Hospital, Banjara hills, Telangana, \\ Hyderabad, India \\ ORCID: https://orcid.org/0000-0002-4805-6252 \\ ${ }^{\mathrm{b}}$ Department of Biostatistics, CARE Hospital, Banjara hills, Telangana, \\ Hyderabad, India
}

Submitted 4 April 2021; Accepted 6 August 2021

\begin{abstract}
Summary
Background and objectives High-resolution ultrasonography (HRUS) has become a vital imaging tool in the management of leprosy. This case-control study analyzed the sonographic data on median nerves in leprosy and healthy controls to identify the features characteristic of leprosy.

Methods Newly diagnosed and treatment naïve Hansen's patients of both sexes and aged $>16$ years were included in the study. The control group included prospectively enrolled healthy subjects. Nerve conduction studies were performed in all. HRUS of the median nerve was performed using a Philips HD15 machine. HRUS parameters studied included cross-sectional area (CSA) of the nerve, fascicular architecture and abnormal blood flow (by colour Doppler). CSA was measured at the wrist (S1), $5 \mathrm{~cm}$ above the wrist (S2), $10 \mathrm{~cm}$ above the wrist (S3), mid-forearm (S4) and at the elbow (S5).

Results 30 median nerves from 22 cases of leprosy and 30 nerves from 15 healthy subjects were compared. Among cases, 8 were borderline tuberculoid, 9 borderline lepromatous, 3 lepromatous leprosy, and 2 indeterminate leprosy. Abnormal motor (76.7\%) and sensory conduction (96.7\%) was noted in the patient group. The mean CSA was $18.5 \mathrm{~mm}^{2}$ at $\mathrm{S} 1,20.3 \mathrm{~mm}^{2}$ at $\mathrm{S} 2,14.1 \mathrm{~mm}^{2}$ at $\mathrm{S} 3,9.1 \mathrm{~mm}^{2}$ at $\mathrm{S} 4$, and $8.1 \mathrm{~mm}^{2}$ at S5. The CSA at S1 and S2 were significantly higher compared to other sites. CSA values were significantly higher in patients compared to controls. The fascicular architecture was distorted in patients - grade II (33.3\%), III (40.0\%) and IV (20\%), and hypervascularity was noted in $26.6 \%$.
\end{abstract}

Correspondence to: Y. Muralidhar Reddy, Consultant Neurologist, CARE Hospital, Banjara Hills, India (Tel.: 9912329342; e-mail: muralidharnims@gmail.com) 
Conclusion HRUS depicted characteristic features of the median nerve in leprosy maximum enlargement in the distal forearm with distorted fascicular architecture.

Keywords: Hansen's disease, median nerve, nerve enlargement, distorted fascicular architecture, hypervascularity

\section{Introduction}

Hansen's disease, commonly known as leprosy, is a chronic debilitating disease of the skin and peripheral nerves caused by infection with Mycobacterium leprae. ${ }^{1}$ Despite the reduced incidence of this neglected tropical disease in most countries worldwide, India is one of the substantial contributors to the global disease burden of leprosy. According to the recent WHO report, India reported 120,334 newly diagnosed patients with leprosy in 2018 and is the country with the highest incidence rate of leprosy in the South East Asia region. ${ }^{2}$

During the clinical course of the disease, M. leprae infects Schwann cells located in the peripheral nerves, leading to damage to these nerves, ultimately manifesting irreversible deformities and functional disabilities of limbs. ${ }^{3}$ The peripheral nerve enlargement occurs early in the disease course, even before the initial clinical symptoms, and if left undiagnosed and untreated, may result in irreversible nerve damage. Therefore, early detection of nerve damage is the most crucial aspect in the management of patients with leprosy. ${ }^{4}$

High-resolution ultrasonography (HRUS) has gained prominence as a novel non-invasive imaging technique for assessing nerve morphology. ${ }^{5,6}$ The ability of HRUS to assess the extent of nerve damage and treatment efficacy in leprosy has made this technique an indispensable tool in managing this disease. ${ }^{7,8}$ Sonographic features of active leprosy include extensive nerve enlargement, distorted fascicular architecture, abnormal vascularity and epineural thickening. ${ }^{9}$

The most commonly involved nerve in Hansen's disease is the ulnar nerve. Several previous case-control studies have provided evidence validating the use of HRUS in the early diagnosis of ulnar neuropathy in leprosy and differentiating it from other causes. ${ }^{10,11}$ It was shown that extensive enlargement of the ulnar nerve above the medial epicondyle is characteristic of leprosy. ${ }^{12}$ However, until now there is only one study describing sonographic median nerve enlargement systematically in Hansen's disease. ${ }^{13}$ Therefore, in the present case-control study, we aimed to study the characteristic features of median neuropathy due to leprosy on HRUS.

\section{Patients and methods}

This study is a retrospective analysis of patients with Hansen's disease who visited the Outpatient Department of Neurology, CARE hospital, Hyderabad, Telangana state, India, between May 2015 and July 2019. Data from healthy controls for comparison were collected prospectively. The study was conducted following the ethical principles in the Declaration of Helsinki. The Institutional Ethics Committee approved the study protocol (Ref. No. IEC/CARE/20455/2020/IIS; approved on 13-May-2020). Written informed consent was obtained from all the healthy participants; however, a consent waiver for the retrospective cases was approved by IEC.

\section{SUBJECTS}

Patients with newly diagnosed, untreated Hansen's disease aged more than 16 years were included, irrespective of gender. The diagnosis of leprosy was made by slit-skin smear 
or skin biopsy. The latter was done in selected patients in those with negative slit-skin smears. Median neuropathy was confirmed by clinical examination. Patients with a history of mechanical trauma or surgery around the region of the median nerve or those with other polyneuropathies including alcoholism, diabetes, amyloidosis, and neurofibromatosis were excluded from the study. Fifteen age and sex-matched healthy subjects were included in the control group. Patients were categorized by the Ridley-Jopling classification system based on clinical features. In those who underwent skin biopsy, classification was done based on histopathological findings.

\section{CLINICAL AND ELECTROPHYSIOLOGICAL EVALUATION}

All patients and healthy controls underwent detailed clinical evaluation by the neurologist (YMR) for any symptoms and signs of median nerve disease. Symptoms of thenar muscle weakness were noted and graded by the modified research council (MRC) scale. Positive and negative sensory symptoms and objective sensory deficits of the lateral half of palm, thumb and index finger were also noted. All patients were categorised according to the RidleyJopling classification. Nerve conduction studies of median motor nerves and median sensory nerves were carried out in all subjects as per the American Academy of Neuromuscular and Electrodiagnostic Medicine (AANEM) protocol on a Synergy electrodiagnostic system by a senior qualified neuro-technologist (KESS). Sensory conduction study was done by orthodromic technique. The electrodiagnostic evaluation was done with the skin temperature kept at $32{ }^{\circ} \mathrm{C}$.

\section{HIGH-RESOLUTION ULTRASOUND EXAMINATION}

HRUS was performed using a Philips HD15 ultrasound system (Massachusetts, USA) with a 12-3 MHz linear array probe. The sonographic examination of all patients was conducted by a senior neurologist trained in neuromuscular ultrasound (YMR) on the same day as the nerve conduction studies and before starting anti-leprosy treatment. The sonographer was not blinded as to whether the subject belonged to the patient or the control group. The median nerve was traced from the wrist proximally until the mid-arm, with the subject placed in the supine position. The maximum cross-sectional area (CSA) of the nerve was measured by the freehand delimitation technique at the inner hyperechoic rim of the nerve. The CSA was measured at five locations-proximal wrist crease (S1), $5 \mathrm{~cm}$ above $\mathrm{S} 1$ (S2), $10 \mathrm{~cm}$ above S1 (S3), mid-point of the line joining elbow crease and S1 (S4), and at elbow crease (S5). The fascicular architecture was graded 0, I, II, III and IV based on the echogenicity at the maximum swelling point of the nerve. The regular honeycomb fascicular pattern was graded as 0 , mild hypoechogenicity $(<50 \%)$ as grade I, obvious hypoechogenicity $(\geq 50 \%)$ as grade II, complete loss of echogenicity (100\%) as grade III and hyperechogenicity as grade IV (Figure 1A-E). Doppler evaluation of the nerve was done using colour Doppler with the pulse repetition frequency of $0.7-1 \mathrm{kHz}$ and Doppler gain of 55-60. Any intraneural or perineural vascularity was recorded. All measurements were done in the transverse section.

\section{STATISTICAL ANALYSIS}

Data were analyzed using SPSS version 23.0. Quantitative variables were presented as mean (standard deviation (SD)), and qualitative variables were presented as frequency, and percentage. An unpaired $T$-test was done as a test of significance for continuous data. A test result was considered significant if the $P$-value was $\leq 0.05$. 


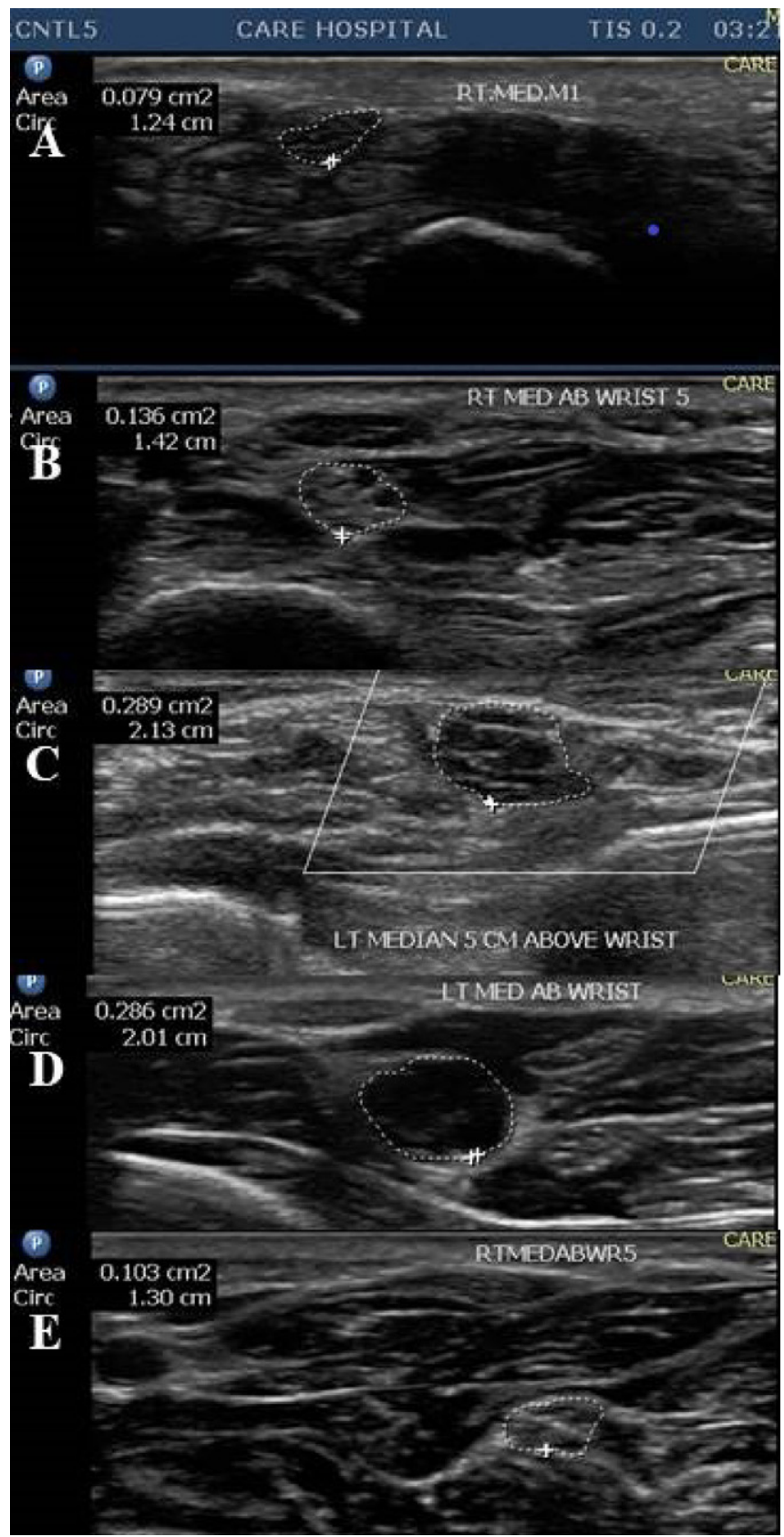

Figure 1. Fascicular grading with examples grade 0 (A); grade 1 (B); grade 2 (C); grade 3 (D); grade 4 (E).

\section{Results}

DEMOGRAPHIC DATA

Thirty median nerves (cases) from 22 Hansen's patients were included in the analysis. Among the cases, 18 were men, and 4 were women. The mean (SD) age was 41.7 (15.4) years. 
Table 1. Assessment of sonographic parameters

\begin{tabular}{|c|c|c|c|}
\hline Parameters & Cases $(n=30)$ & Controls $(n=30)$ & $p$-value \\
\hline \multicolumn{4}{|l|}{ Mean CSA at $\left(\mathrm{mm}^{2}\right)$} \\
\hline Wrist & $18.5(6.8)$ & $7.4(1.2)$ & $<0.001$ \\
\hline $5 \mathrm{~cm}$ above wrist & $20.3(6.8)$ & $6.1(0.9)$ & $<0.001$ \\
\hline $10 \mathrm{~cm}$ above wrist $\left(n^{*}=20\right)$ & $13.3(4.8)$ & $5.5(0.8)$ & $<0.001$ \\
\hline Mid forearm $\left(n^{*}=22\right)$ & $8.1(3.2)$ & $5.4(0.9)$ & 0.001 \\
\hline Elbow $\left(n^{*}=21\right)$ & $8.8(3.8)$ & $5.7(0.6)$ & $<0.001$ \\
\hline \multicolumn{4}{|l|}{ Fascicular architecture, $n(\%)$} \\
\hline Grade I & $2(6.6)$ & & \\
\hline Grade II & $10(33.3)$ & - & - \\
\hline Grade III & $12(40)$ & & \\
\hline Grade IV & $6(20)$ & & \\
\hline Hypervascularity, $n(\%)$ & $8(26.6)$ & - & - \\
\hline
\end{tabular}

$8(36.4 \%)$ were classified as borderline lepromatous (BL), 9 (40.9\%) as borderline tuberculoid (BT), $2(9.09 \%)$ as indeterminate (IN) and $3(13.6 \%)$ as lepromatous leprosy (LL), as per the Ridley-Jopling classification. Skin biopsy findings were used for classifying in 5 (22.7\%) cases, of which three were BT, and two were IN. 30 median nerves from 15 healthy volunteers were included as controls; in the control group, the mean (SD) age was 39.9 (12.4) years, 12 were men, and 3 were women.

\section{CLINICAL AND ELECTROPHYSIOLOGICAL FINDINGS}

On clinical examination, combined sensory and motor deficits were noted in $25(83.3 \%)$, and sensory deficit alone was noted in $5(16.7 \%)$. Three $(10 \%)$ had pain and tenderness of the median nerve in the distal forearm and wrist. Seven (23.33\%) reported pain and tenderness along the median nerve in the distal forearm. In nerve conduction studies, of the thirty nerves (cases), both motor and sensory conduction abnormalities were found in 23 (76.6\%), only sensory abnormalities in $6(20 \%)$. One nerve $(3.33 \%)$ showing normal conduction study results had sensory deficits in the median nerve distribution on examination.

\section{HRUS FINDINGS}

Data on median nerve CSA for cases at S3, S4 and S5, were available only for 20, 22 and 21 nerves, respectively. HRUS observations showed that the average (SD) median nerve CSA was $18.5(6.8) \mathrm{mm}^{2}$ at $\mathrm{S} 1,20.3(6.8) \mathrm{mm}^{2}$ at $\mathrm{S} 2,13.3(4.8) \mathrm{mm}^{2}$ at $\mathrm{S} 3,8.1(3.2) \mathrm{mm}^{2}$ at $\mathrm{S} 4$, and $8.8(3.8) \mathrm{mm}^{2}$ at S5 (Table 1). The comparative analysis of CSA values between cases and control groups showed significantly higher mean CSA $(p<0.001)$ at each site in cases than in the control group (Figure 2). Comparing the CSA values among different sites showed that CSA at S1 and S2 were significantly higher $(p<0.001)$ compared to other sites.

The fascicular pattern analyses of nerves showed that the majority of nerves were classified as grade II in $10(33.3 \%)$ cases and grade III in $12(40.0 \%)$ cases, whereas $6(20 \%)$ nerves showed hyperechogenicity (IV). Abnormal vascularity was noted on Doppler examination in eight $(26.6 \%)$ median nerves (Table 1). Nerve CSA and fascicular grade at five sites in the whole cohort are shown in the bubble diagram (Figure 3). A hand sketch of the median nerve based on these results (Figure 4) and HRUS pictures (Figure 5) highlight maximum nerve enlargement in the distal forearm. 


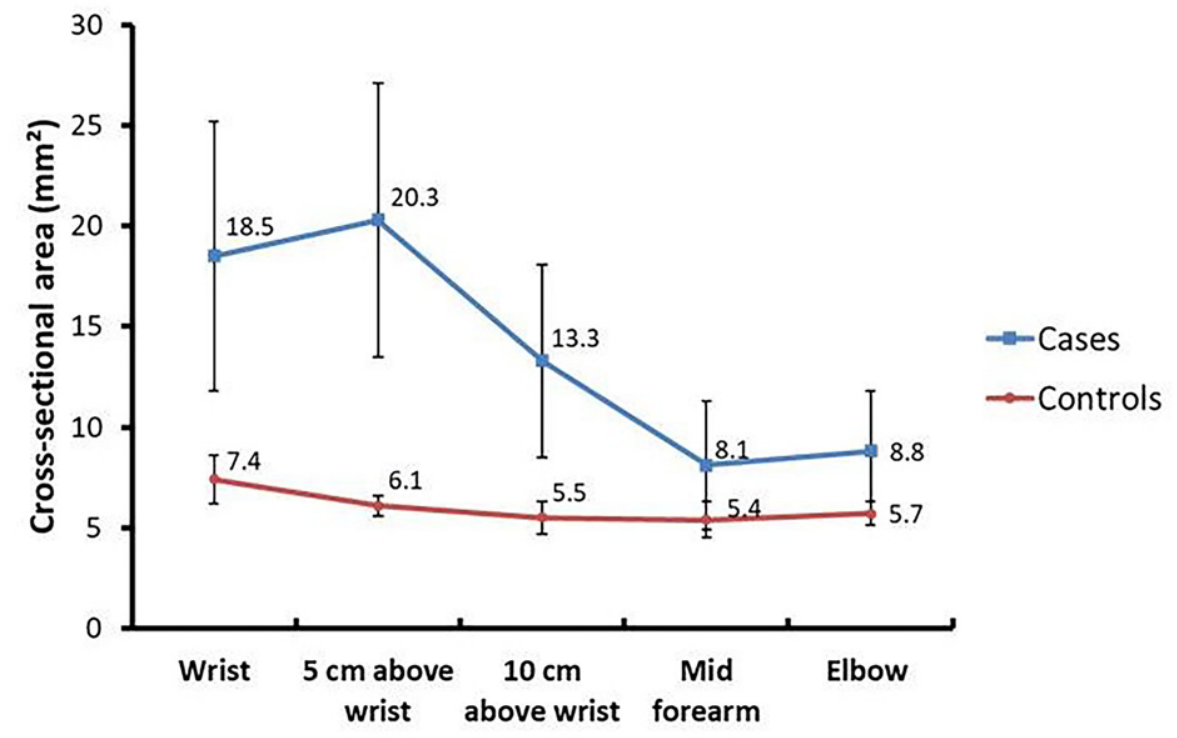

\begin{tabular}{|c|c|c|c|c|c|}
\hline $\begin{array}{c}\text { Cases } \\
(n)\end{array}$ & 30 & 30 & 20 & 22 & 21 \\
\hline $\begin{array}{c}\text { Controls } \\
(n)\end{array}$ & 30 & 30 & 30 & 30 & 30 \\
\hline
\end{tabular}

Figure 2. Comparison of the CSA at various sites between cases and control groups.

\section{Discussion}

Peripheral neuropathy due to leprosy is a well-established fact. ${ }^{3}$ Sonographic observations from peripheral nerves using HRUS help to understand the location and degree of nerve enlargement, fascicular architectural pattern and vascularity of the nerve. ${ }^{12,14}$ Although, several previous studies have reported a unique pattern of morphological changes of the ulnar nerve, the studies evaluating median nerve pattern are scant at global and national levels. Given this lacuna, the present study assessed sonographic features of median nerve neuropathy in a cohort of patients with Hansen's disease from a hospital situated in the southern part of India.

In the present study, overall observations indicate two unique aspects of median nerve enlargement in Hansen's disease. Firstly, the median nerve is diffusely enlarged compared to healthy controls. The median nerve was two-fold larger at the wrist, three-fold larger at 5 $\mathrm{cm}$ above the wrist, two-fold larger at $10 \mathrm{~cm}$ above the wrist and 1.5-fold larger at mid-forearm and elbow in patients with Hansen's disease compared with the control group. Secondly, the median nerve is enlarged more at the wrist and $5 \mathrm{~cm}$ above the wrist than $10 \mathrm{~cm}$ above the wrist, mid-forearm, and elbow in leprosy, suggesting maximum enlargement in the distal forearm. The median nerve can be involved either as an isolated mononeuropathy or as part of a polyneuropathy. Common causes of mononeuropathy include entrapments such as carpal tunnel syndrome, pronator syndrome, varying degrees of trauma, tumours (including Schwannoma, neurofibroma, neurosarcoma and neurilemmoma), and ganglion cysts. Common causes of polyneuropathies include vasculitis and immune-mediated neuropathies such as inflammatory demyelinating neuropathies, sarcoidosis, and hereditary neuropathies, apart 


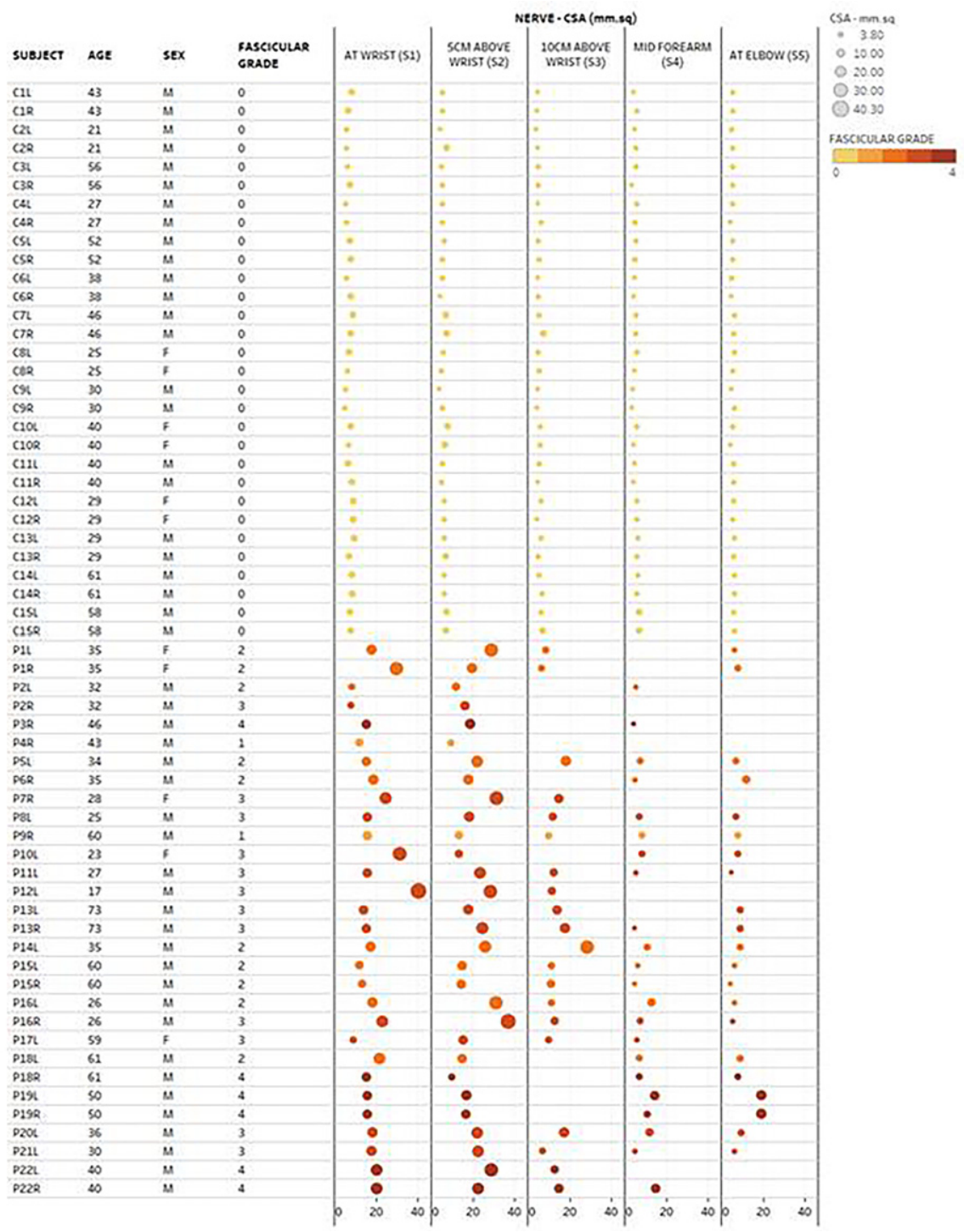

Figure 3. Bubble diagram depicting CSA and fascicular pattern of whole cohort.

from leprosy. ${ }^{15}$ While enlargement is very focal in entrapments, tumors and trauma, it is diffuse, multifocal and more proximal in non-Hansen's polyneuropathies. ${ }^{16,17}$ Therefore, the peculiar enlargement pattern identified in this paper appears unique to leprosy. Nagappa et al. showed that the median nerve in leprosy was maximally enlarged proximal to wrist crease with gradual tapering proximally while it enlarged most at the distal wrist crease in carpal tunnel syndrome. ${ }^{13}$ The median nerve is a deep nerve and is not easily palpable, unlike the ulnar, radial, common peroneal and posterior tibial nerves. Therefore, HRUS is of immense value in detecting median nerve enlargement and in evaluating the echo texture and blood flow as highlighted in our study. This enlargement pattern of the median nerve, which is more 
A

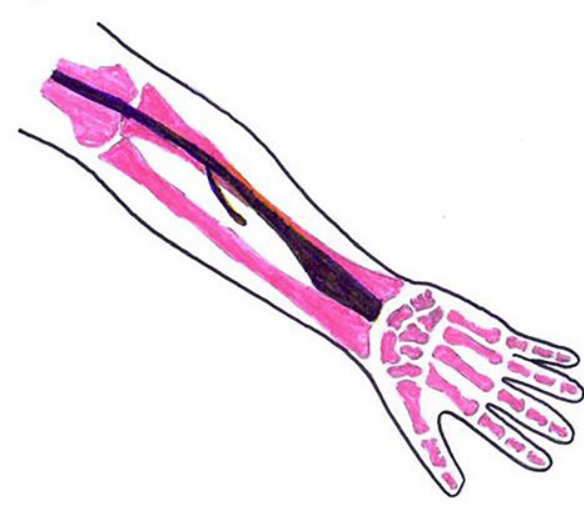

B

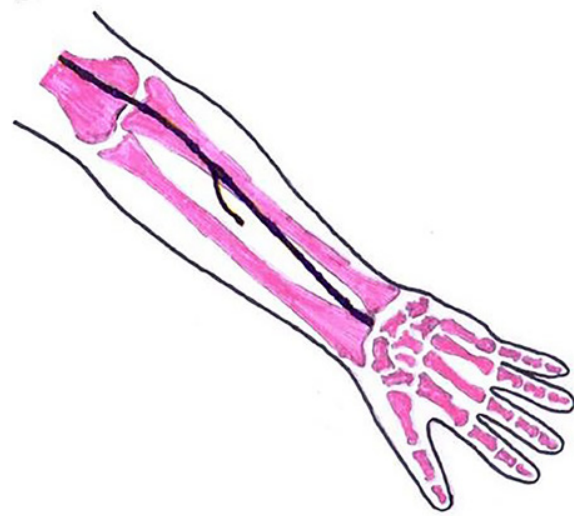

Figure 4. (A, B) Hand drawn sketch showing the pattern of median nerve enlargement in leprosy (A) and healthy control (B).

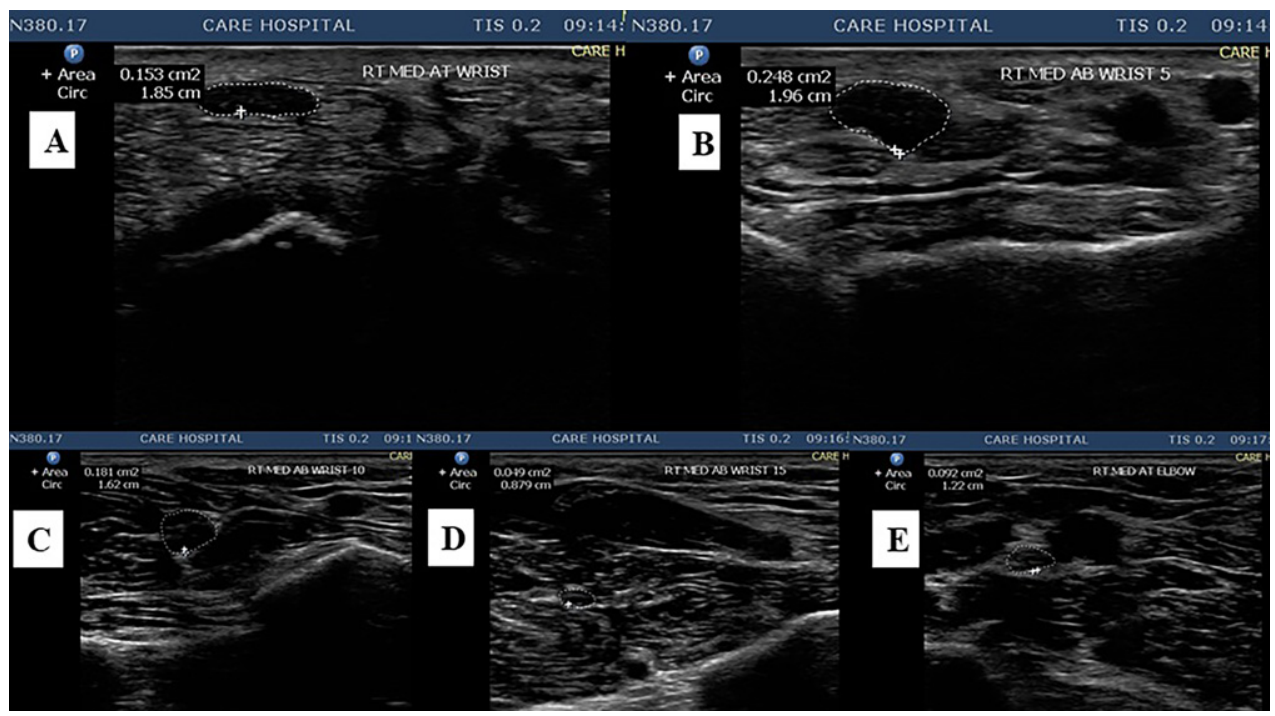

Figure 5. (A-E) HRUS images of median nerve in a Hansen's patient showing enlargement at S1, S2, S3, S4 and S5 along with distorted fascicular architecture.

prominent proximal to the fibro-osseous carpal tunnel, is similar to studies of the ulnar nerve, which shows maximal enlargement proximal to the cubital tunnel. ${ }^{18-20}$ Bathla et al. compared the HRUS pattern of ulnar nerve enlargement in 30 nerves of leprosy patients with 30 healthy controls. They concluded that the increase in ulnar nerve CSA occurred throughout the arm in patients compared with controls, and reported the maximum enlargement between the ulnar sulcus and axilla, peaking at four centimeters above the sulcus. ${ }^{18}$ Gupta et al. compared the ulnar nerve CSA at three levels in leprosy patients-four centimetres above the elbow, deep to the cubital tunnel and below the medial epicondyle between flexor carpi ulnaris and flexor 
digitorum profundus - with controls, finding that the ulnar nerve was enlarged at all three sites in leprosy. Larger CSA values were noted above the elbow. ${ }^{19}$

In this study, most of the median nerves showed moderate to severe distortion of fascicular architecture, and nearly $30 \%$ showed abnormal intraneural vascularity. These findings, though not specific features of the median nerve in leprosy, indicate severe nerve damage and a disrupted blood-nerve barrier. Previous studies on leprous neuropathy reported a range of fascicular abnormalities from mild hypoechogenicity to complete loss of architecture and hyperechogenicity. ${ }^{12,14}$ Intraneural vascularity is often seen in patients with active neuritis, but rarely without it. ${ }^{21,22}$ Jain et al. reported abnormal colour flow in $25 \%$ of the tested median nerves with active disease. ${ }^{14}$ A longitudinal study by Lugao et al. showed intraneural vascularity diminishing after anti-leprosy therapy. They also showed in the same study a case with subclinical intraneural vascularity that progressed to develop active neuritis later. Intraneural vascularity, therefore, can be the first sign of nerve damage, and it may have a role in predicting reactions. ${ }^{7}$ These additional findings, in the presence of enlarged nerves in the distal forearm segment, appear to be typical of Hansen's disease and could prove very useful, especially in patients with a pure neuritic form of leprosy and those with isolated median nerve involvement.

NCS was normal in one of our patients. However, he had sensory deficits on clinical examination and an enlarged nerve on HRUS. Elias et al. reported three cases of ulnar neuropathy due to leprosy with abnormal HRUS and normal NCS. These findings suggest that HRUS may detect nerve involvement earlier than electrophysiology in leprosy. ${ }^{23}$

Our study is unique in many aspects. Firstly, we included newly diagnosed and treatment naïve patients with leprosy. Many published reports are cross-sectional studies and include patients already on anti-leprosy therapy. These may have affected the findings. Secondly, we used a grading system to report the fascicular abnormalities, unlike many other studies. This grading system is helpful to know the severity of nerve damage. Thirdly, we have compared the nerve CSA at different locations along the course and showed intraneural variability, which is less often reported in other nerves except for studies of the ulnar nerve. However, our study has some limitations. Firstly, the study's retrospective design limits the data collection for various additional parameters that would have been helpful. We did not have all data in the patient group at S3, S4 and S5. Secondly, the median nerve data of the arm segment was very scanty and therefore excluded deliberately to maintain uniformity of the data. Thirdly, the unblinded assessment of nerve on HRUS could have led to some bias. Fourthly, the small sample size makes our findings only suggestive.

\section{Conclusion}

Overall observations indicate that HRUS depicted characteristic features of leprosy in the median nerve. Recognising the unique sonographic enlargement pattern along with distorted fascicular architecture and abnormal colour flow could help clinicians identify median nerve damage quite early in Hansen's disease. Therefore, HRUS can be considered an essential diagnostic tool to determine median nerve neuropathy among patients with leprosy; however, large-scale prospective studies are necessary to validate these findings.

\section{Review board approval}

Obtained (Ref. No. IEC/CARE/20455/2020/IIS; approved on 13-May-2020). 


\section{Conflict of interest}

Authors report no conflict of interest.

\section{Funding}

No funding was paid for this research.

\section{Contributorship}

YMR has conceptualised the paper, done the clinical examination and sonography of all subjects and controls, written the manuscript. JMKM has contributed patient information and revised the manuscript; SKJ and LP have contributed patient information; KESS has done the electrodiagnostics; AP and RN have compiled the data; SK has done the statistical analysis.

\section{Patient consent}

Consent was taken from all healthy controls. Consent waiver was approved by Institutional Ethics Committee for patients.

\section{Data sharing statement}

The supporting data for this article can be obtained from the corresponding author on request.

\section{Acknowledgements}

Authors acknowledge Mrs. Sindhu for bubble diagram; Mrs. Deepika P for helping in technical work.

\section{References}

1 Britton WJ, Lockwood DN. Leprosy. Lancet, 2004; 363(9416): 1209-1219. doi:10.1016/S0140-6736(04)1595 2-7.

2 World Health Organization. Global Leprosy Update, 2018: moving towards a leprosy free world. Wkly Epidemiol Rec, 2019; 94(35/36): 389-412.

3 Ooi WW, Srinivasan J. Leprosy and the peripheral nervous system: basic and clinical aspects. Muscle Nerve, 2004; 30(4): 393-409. doi:10.1002/mus.20113.

4 de Freitas MR, Said G. Leprous neuropathy. Handb Clin Neurol, 2013; 115: 499-514. doi:10.1016/B978-0-44 4-52902-2.00028-X.

5 Beekman R, Visser LH. High-resolution sonography of the peripheral nervous system-a review of the literature. Eur J Neurol, 2004; 11(5): 305-314. doi:10.1111/j.1468-1331.2004.00773.x.

6 Lawande AD, Warrier SS, Joshi MS. Role of ultrasound in evaluation of peripheral nerves. Indian J Radiol Imaging, 2014; 24: 254-258. doi:10.4103/0971-3026.137037.

7 Lugão HB, Frade MA, Marques W Jr, Foss NT, Nogueira-Barbosa MH. Ultrasonography of leprosy neuropathy: a longitudinal prospective study. PLoS Negl Trop Dis, 2016; 10(11): e0005111. doi:10.1371/journal.pntd.0005 111.

8 Chaduvula MV, Visser LH, Suneetha S, Suneetha L, Devaraju B, Ellanti R, Raju R, Jain S. High-resolution sonography as an additional diagnostic and prognostic tool to monitor disease activity in leprosy: a two-year prospective study. Ultraschall Med, 2018; 39(1): 80-89. doi:10.1055/s-0042-108430.

9 Reddy MY, Pidaparthi L, Tourani V, Penneru A, Murthy J. High-resolution ultrasound features of greater auricular nerve in leprosy. Postgrad Med J, 2020; 96(1137): 443. doi:10.1136/postgradmedj-2020-137703.

10 Ashwini B, NandaKishore B, Basti RS et al. Ultrasound as a diagnostic modality for the involvement of peripheral nerves in leprosy. Indian J Lepr, 2018; 90: 1-14.

11 Frade MA, Nogueira-Barbosa MH, Lugão HB, Furini RB, Marques Júnior W, Foss NT. New sonographic measures of peripheral nerves: a tool for the diagnosis of peripheral nerve involvement in leprosy. Mem Inst Oswaldo Cruz, 2013; 108(3): 257-262. doi:10.1590/S0074-02762013000300001. 
12 Bathala L, Kumar K, Pathapati R, Jain S, Visser LH. Ulnar neuropathy in Hansen disease: clinical, highresolution ultrasound and electrophysiologic correlations. J Clin Neurophysiol, 2012; 29(2): 190-193. doi:1 0.1097/WNP.0b013e31824d969c.

13 Nagappa M, Pujar GS, Keshavan AH, Bathala L, Jain RD, Das A, Mehndiratta MM, Visser LH, Kumar HM. Sonographic pattern of median nerve enlargement in Hansen's neuropathy. Acta Neurol Scand, 2021; 144: 155160. doi:10.1111/ane.13432.

14 Jain S, Visser LH, Praveen TL, Rao PN, Surekha T, Ellanti R, Abhishek TL, Nath I. High-resolution sonography: a new technique to detect nerve damage in leprosy. PLoS Negl Trop Dis, 2009; 3(8): e498. doi:10.1371/journal. pntd.0000498.

15 Singla M, Sharma MK, Khurana D, Lal V. Role of high frequency ultrasound in diagnosing carpal tunnel syndrome as compared with conventional nerve conduction studies. Ann Indian Acad Neurol, 2020; 23(5): 649_ 655. doi:10.4103/aian.AIAN_469_19.

16 Padua L, Paolasso I, Pazzaglia C, Granata G, Lucchetta M, Erra C, Coraci D, De Franco P, Briani C. High ultrasound variability in chronic immune-mediated neuropathies. Review of the literature and personal observations. Rev Neurol (Paris), 2013; 169(12): 984-990. doi:10.1016/j.neurol.2013.07.028.

17 Kramer M, Grimm A, Winter N, Dörner M, Grundmann-Hauser K, Stahl JH, Wittlinger J, Kegele J, Kronlage C, Willikens S. Nerve ultrasound as helpful tool in polyneuropathies. Diagnostics (Basel), 2021; 11(2): 211. doi:10.3390/diagnostics11020211.

18 Bathala L, N Krishnam V, Kumar HK, Neladimmanahally V, Nagaraju U, Kumar HM, Telleman JA, Visser LH. Extensive sonographic ulnar nerve enlargement above the medial epicondyle is a characteristic sign in Hansen's neuropathy. PLoS Negl Trop Dis, 2017; 11(7): e0005766. doi:10.1371/journal.pntd.0005766.

19 Gupta S, Bhatt S, Bhargava SK, Singal A, Bhargava S. High resolution sonographic examination: a newer technique to study ulnar nerve neuropathy in leprosy. Lepr Rev, 2016; 87(4): 464-475.

20 Lugão HB, Nogueira-Barbosa MH, Marques W Jr, Foss NT, Frade MA. Asymmetric nerve enlargement: a characteristic of leprosy neuropathy demonstrated by ultrasonography. PLoS Negl Trop Dis, 2015; 9(12): e0004276. doi:10.1371/journal.pntd.0004276.

21 Garbino JA, Heise CO, Marques W Jr. Assessing nerves in leprosy. Clin Dermatol, 2016; 34(1): 51-58. doi:10 .1016/j.clindermatol.2015.10.018.

22 Martinoli C, Derchi LE, Bertolotto M, Gandolfo N, Bianchi S, Fiallo P, Nunzi E. US and MR imaging of peripheral nerves in leprosy. Skeletal Radiol, 2000; 29(3): 142-150. doi:10.1007/s002560050584.

23 Elias J Jr, Nogueira-Barbosa MH, Feltrin LT, Furini RB, Foss NT, Marques W Jr, dos Santos AC. Role of ulnar nerve sonography in leprosy neuropathy with electrophysiologic correlation. J Ultrasound Med, 2009; 28(9): 1201-1209. doi:10.7863/jum.2009.28.9.1201. 